\title{
SUPERSONIC FLOW SEPARATION WITH APPLICATION TO ROCKET ENGINE NOZZLES
}

by

Jan Östlund

June 2004

Technical reports from

Royal Institute of Technology

Department of Mechanics

S-100 44 Stockholm, Sweden 
Akademisk avhandling som med tillstånd av Kungliga Tekniska Högskolan i Stockholm framlägges till offentlig granskning för avläggande av teknologie doktorsexamen torsdagen den 10 juni 2004 kl 10.00 i Kollegiesalen, Administrationsbyggnaden, Kungliga Tekniska Högskolan, Vallhallavägen 79, Stockholm.

C Jan Östlund 2004

Universitetsservice US-AB, Stockholm 2004 
Jan Östlund 2004

Supersonic flow separation with application to rocket engine nozzles

Department of Mechanics, Royal Institute of Technology

SE-100 44 Stockholm, Sweden

\begin{abstract}
The increasing demand for higher performance in rocket launchers promotes the development of nozzles with higher performance, which basically is achieved by increasing the expansion ratio. However, this may lead to flow separation and ensuing instationary, asymmetric forces, so-called side-loads, which may present life-limiting constraints on both the nozzle itself and other engine components. Substantial gains can be made in the engine performance if this problem can be overcome, and hence different methods of separation control have been suggested. However, none has so far been implemented in full scale, due to the uncertainties involved in modeling and predicting the flow phenomena involved.

In the present work the causes of unsteady and unsymmetrical flow separation and resulting side-loads in rocket engine nozzles are investigated. This involves the use of a combination of analytical, numerical and experimental methods, which all are presented in the thesis. A main part of the work is based on sub-scale testing of model nozzles operated with air. Hence, aspects on how to design sub-scale models that are able to capture the relevant physics of full-scale rocket engine nozzles are highlighted. Scaling laws like those presented in here are indispensable for extracting side-load correlations from sub-scale tests and applying them to full-scale nozzles.
\end{abstract}

Three main types of side-load mechanisms have been observed in the test campaigns, due to: (i) intermittent and random pressure fluctuations, (ii) transition in separation pattern and (iii) aeroelastic coupling. All these three types are described and exemplified by test results together with analysis. A comprehensive, up-to-date review of supersonic flow separation and side-loads in internal nozzle flows is given with an in-depth discussion of different approaches for predicting the phenomena. This includes methods for predicting shock-induced separation, models for predicting side-load levels and aeroelastic coupling effects. Examples are presented to illustrate the status of various methods, and their advantages and shortcomings are discussed.

A major part of the thesis focus on the fundamental shock-wave turbulent boundary layer interaction (SWTBLI) and a physical description of the phenomenon is given. This description is based on theoretical concepts, computational results and experimental observation, where, however, emphasis is placed on the rocket-engineering perspective. This work connects the industrial development of rocket engine nozzles to the fundamental research of the SWTBLI phenomenon and shows how these research results can be utilized in real applications. The thesis is concluded with remarks on active and passive flow control in rocket nozzles and directions of future research.

The present work was performed at VAC's Space Propulsion Division within the framework of European space cooperation.

Keywords: turbulent, boundary layer, shock wave, interaction, overexpanded, rocket nozzle, flow separation, control, side-load, experiments, models, review. 


\section{PREFACE}

This thesis is based on the work contained in the following papers:

1. Mattsson ${ }^{1} \mathrm{~J}$, Högman $\mathrm{U}$, and Torngren $\mathrm{L}$

"A Sub-Scale Test Programme on Investigation of Flow Separation and SideLoads in Rocket Nozzles",

Proceedings of the 3rd European Symposium on Aerothermodynamics of Space Vehicles, ESA-ESTEC, Netherlands, November 24-26, 1998, ESA SP426.

2. Östlund $\mathrm{J}$ and Bigert $\mathrm{M}$

"A Subscale Investigation on Side-Loads in Sea Level Rocket Nozzles"

$35^{\text {th }}$ AIAA/ASME/SAE/ASEE Joint Propulsion Conference and Exhibit, AIAA Paper 99-2759, June 1999.

3. Östlund $\mathrm{J}$ and Jaran $\mathrm{M}$

"Assessment of Turbulence Models in Overexpanded Rocket Nozzle Flow Simulations"

$35^{\text {th }}$ AIAA/ASME/SAE/ASEE Joint Propulsion Conference and Exhibit, AIAA Paper 99-2583, June 1999

4. Östlund J, Damgaard T and Frey M

"Side-Load Phenomena in Highly Overexpanded Rocket Nozzles"

Accepted for publication in Journal of Propulsion and Power (based on AIAA

Paper 2001-3684 presented at 37 $7^{\text {th }}$ AIAA/ASME/SAE/ASEE Joint Propulsion Conference and Exhibit, which received "best paper" award).

5. Östlund J and Muhammad-Klingmann B

"Supersonic Flow Separation with application to Rocket Engine Nozzles"

Accepted in revised form for publication in Applied Mechanics Reviews

Relevant scientific publications not included in this thesis:

6. Mattsson ${ }^{1} \mathrm{~J}$

"Separation Analysis in Conventional Bell Nozzles"

In Proceedings of European Seminar on Rocket Nozzle Flows, CNES, Paris, 12-14 October 1998.

\footnotetext{
${ }^{1}$ Jan Östlund changed his name from Jan Mattsson in January 1999
} 
7. Mattsson ${ }^{1} \mathrm{~J}$

"Analysis of Flow Separation in Viking Nozzle"

In Proceedings of European Seminar on Rocket Nozzle Flows, CNES, Paris, 12-14 October 1998.

8. Mattsson ${ }^{1} \mathrm{~J}$

"Subscale Testing of Flexible Nozzles"

In Proceedings of European Seminar on Rocket Nozzle Flows, CNES, Paris, 12-14 October 1998.

9. Mattsson ${ }^{1} \mathbf{J}$

"Aeroelastic Modelling of Side Loads in Nozzles"

In Proceedings of European Seminar on Rocket Nozzle Flows, CNES, Paris, 12-14 October 1998.

10. Hagemman G, Terhardt M, Frey M, Reijasse P, Onofri M, Nasuti F and Östlund J

"Flow Separation and Side-Loads in Rocket Nozzles"

4th International Symposium on Liquid Space Propulsion, March 12-15, 2000, DLR Lampoldshausen

11. Östlund, J, Damgaard T and Frey M

"Side-Load Phenomena in Highly Overexpanded Rocket Nozzles"

$37^{\text {th }}$ AIAA/ASME/SAE/ASEE Joint Propulsion Conference and Exhibit, AIAA Paper 2001-3684, July 2001.

12. Östlund $\mathrm{J}$

"Flow Processes in Rocket Engine Nozzles with Focus on Flow Separation and Side-Loads"

Licentiate Thesis, TRITA-MEK 2002:09, Department of Mechanics, Royal Institute of Technology, Stockholm, Sweden, 2002.

In addition, the work includes results reported by this author in numerous classified technical notes at VAC, ESA/ESTEC and CNES. 


\section{ACKNOWLEDGEMENTS}

This work has been carried out at the Space Propulsion Division at Volvo Aero Corporation in Trollhättan within the GSTP program and the framework of the European Flow Separation Control Device (FSCD) working group. I would like to express my sincere thanks and appreciation to my supervisor Dr. Barbro Muhammad-Klingmann (Royal Institute of Technology), without whose guidance and support this work would not be possible. I would like to thank my close colleagues Dr. Lars Ljungkrona and Dr. Manuel Frey for their suggestions, remarks and inspiring discussions. Valuable help and suggestions from many people at Volvo Aero Corporation are appreciated and special thanks to those working at the Business Unit Nozzles. I would like to acknowledge all the FSCD members, especially Dr. G Hagemann, Dr. M Terhardt (ASTRIUM), Dr. M Pons, Dr. P Vuillermoz (CNES), R Stark (DLR), Dr. R Schwane (ESTEC), Mr. L Torngren (FOI), Dr. Ph Reijasse (ONERA), Dr. Ph James (SNECMA) and Dr. Alziary de Roquefort (University of Poitiers) for the fruitful cooperation in this field. Last but not least I thank my wife Anna for her encouragement and understanding.

This work has been supported through grants from Volvo Aero Corporation and the Swedish Research Council for Engineering Sciences (TFR contract 285-98717). These sources of support are gratefully acknowledged. 



\section{CONTENTS}

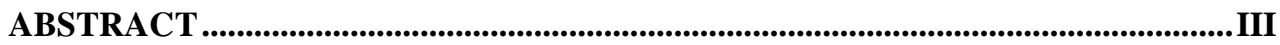

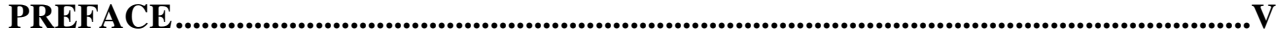

ACKNOWLEDGEMENTS..............................................................................................VII

INTRODUCTION......................................................................................................... 1

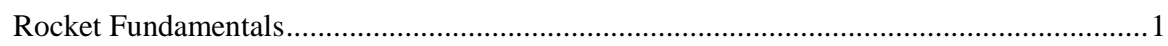

The Main Design Issue of Core Stage Engine Nozzles..........................................................

Undesirable Effects Associated with Flow Separation ……………………………………...

Development Logic for Nozzle Design.............................................................................. 10

SUMMARY OF PAPERS ................................................................................................ 14

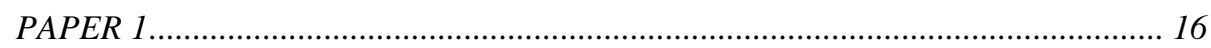

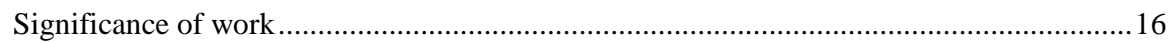

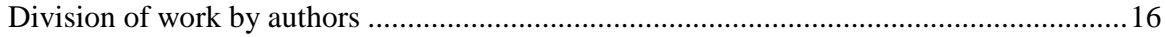

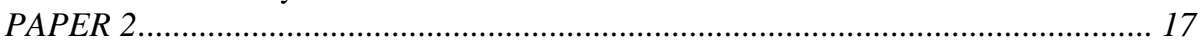

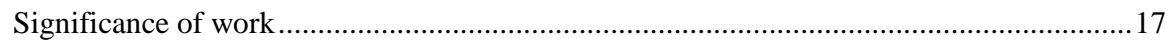

Division of work by authors .......................................................................................... 17

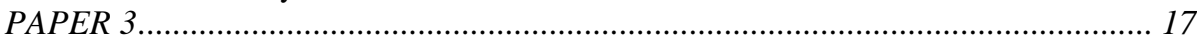

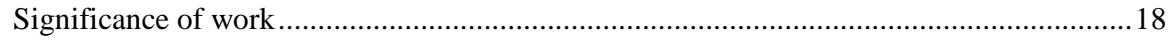

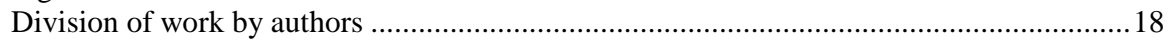

PAPER 4 …

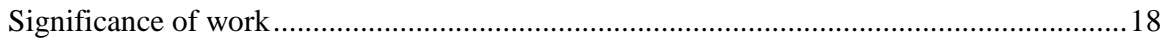

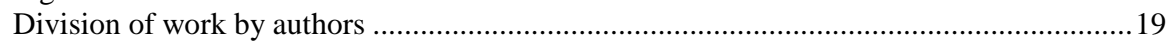

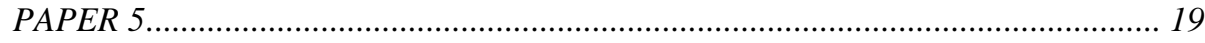

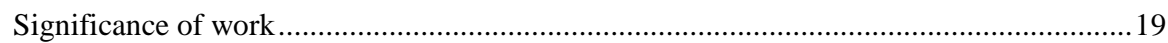

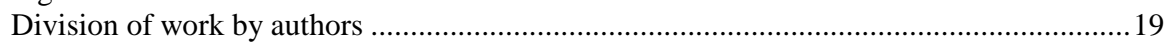

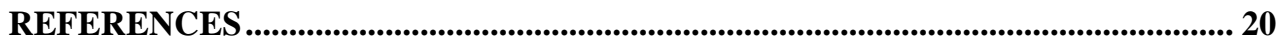





\section{INTRODUCTION}

The valuable services offered by today's satellites are many and varied. They include more secure air traffic control, accurate weather reports, timely warnings of environmental hazards as well as a wider choice of television programs and improvements in health care.

All these services we now take for granted and tend to forget that they would not exist if we did not have rocket launchers capable of placing satellites accurately into space.

\section{Rocket Fundamentals}

The rocket is a device that stores its own propellant mass and expels this mass at high velocity to provide a reaction force, the thrust. As the rocket contains all the propellant itself, it is independent of its environment and, hence, can operate in empty space. There are two groups of rocket propellants, liquids and solids. Many spacecraft launchers involve the use of both types of rockets, for example the solid rocket boosters attached to liquid-propelled rockets. Solid rockets are generally simpler than liquid, but they cannot be shut down once ignited. Liquid engines may be shut down after ignition and conceivably could be re-ignited.

The basic principle driving a rocket engine is the famous Newtonian principle that "to every action there is an equal and opposite reaction." A rocket engine is throwing mass in one direction and benefiting from the reaction that occurs in the other direction as a result, see Figure 1a.

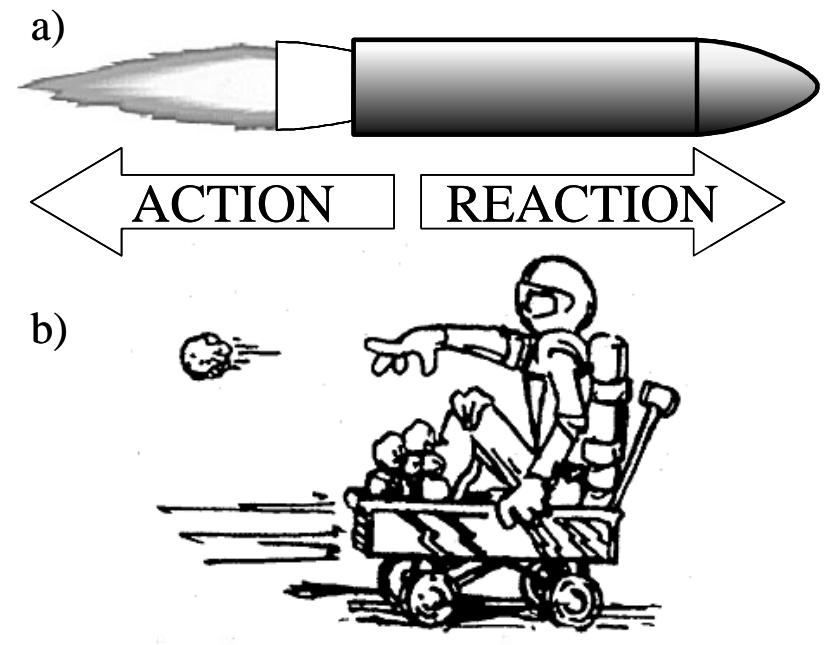

Figure 1. The basic principle of momentum exchange.

a) Rocket, b) One person-rocket (Courtesy cartoon of Humble et al. [1]) 
This concept of "throwing mass and benefiting from the reaction" can be hard to grasp at first, because that does not seem to be what is happening. Rocket engines seem to be about flames and noise and pressure, not "throwing things". To get a better picture we consider an astronaut throwing rocks out of the back of a wagon, see Figure 1b. The astronaut uses his muscles to accelerate the rocks in one direction, leading to an equal but opposite force on the wagon that pushes it in the opposite direction. The thing that controls the speed at which the wagon moves away is the weight of the rocks that he throws and the amount of acceleration that he applies to it. From Newton's Second Law, we know that the force on an object is equal to the rate of change of momentum, so the momentum thrust is

$$
F_{m}=\frac{d m}{d t} v_{e}=\dot{m} v_{e}
$$

where $\dot{m}$ is the mass flow rate and $v_{e}$ is the exit or exhaust velocity of the propellant. If the astronaut wants to generate more thrust, he has two options: increase the mass or increase the velocity of the rock. He can throw a heavier rock or throw a number of rocks one after another (increasing the mass), or he can throw the rock faster. But that is all that he can do.

A rocket engine is generally throwing mass in the form of a high-velocity gas. The engine throws the mass of gas out in one direction in order to get a reaction in the opposite direction. The mass comes from the weight of the propellants that the rocket engine uses. In a liquid rocket engine the propellants (fuel and oxidizer) are injected in to a combustion chamber where it is mixed and burned. Typically, the combustion chamber is a constant diameter duct with sufficient length to allow complete combustion of the propellants before the nozzle accelerates the gas products, see Figure 2. The nozzle is said to begin at the point where the chamber diameter begins to decrease.

Simply stated, the nozzle uses the temperature $\left(T_{0}\right)$ and pressure $\left(p_{0}\right)$ generated in the combustion chamber to create thrust by accelerating the combustion gas to a high supersonic velocity (see Figure 2 ). The nozzle exit velocity $\left(v_{e}\right)$ that can be achieved is governed by the nozzle expansion ratio $\varepsilon$, defined as the ratio between the nozzle exit area and throat area, $\mathcal{E}=A_{e} / A_{t}$.

In addition to the momentum thrust, there are pressure forces acting on the rocket system. Combining the momentum and pressure thrust, the total thrust $(F)$ produced by the rocket engine can be expressed as

$$
F=\dot{m} v_{e}+\left(p_{e}-p_{a}\right) A_{e}
$$

where $p_{e}$ and $A_{e}$ are the pressure and cross section area at the nozzle exit, and $p_{a}$ is the ambient pressure. 


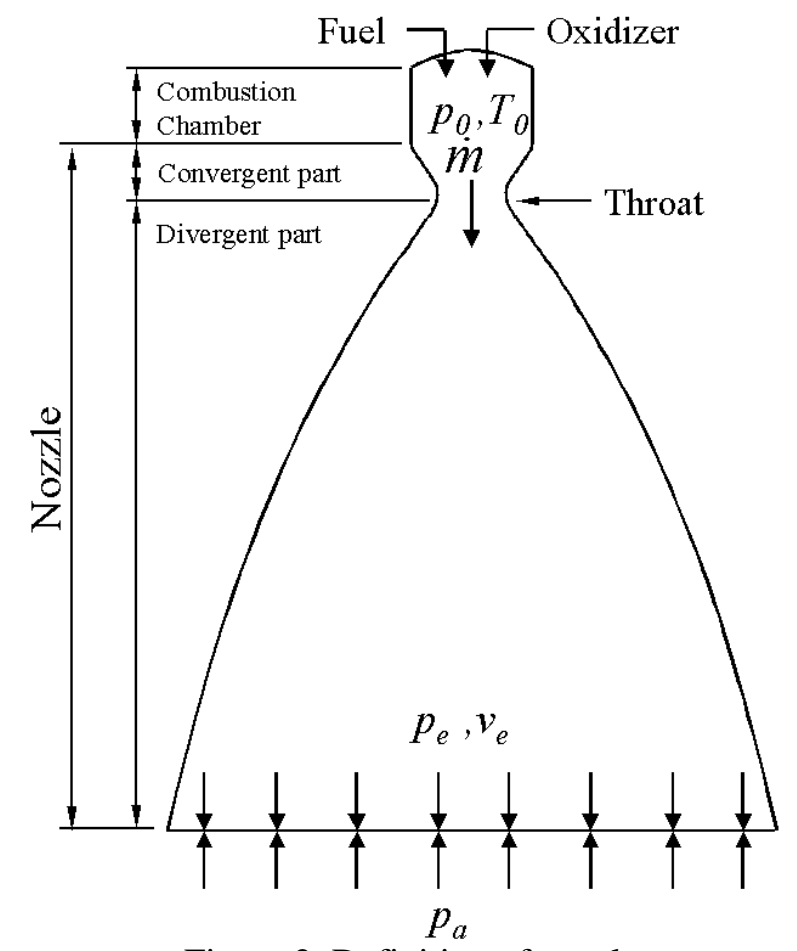

Figure 2. Definition of nozzle.

Besides the thrust, the specific impulse, $I_{s p}$, is an important parameter characterizing a rocket engine. The specific impulse is defined $\mathrm{as}^{2}$

$$
I_{s p}=\frac{F}{\dot{m}}=v_{e}+\frac{\left(p_{e}-p_{a}\right)}{\dot{m}} A_{e}
$$

which is a measure of how well a given propellant flow rate is transformed into thrust.

When inspecting Eq. (2) or Eq. (3), we get the impression that maximizing the exit pressure and velocity would maximize the performance for a given flow rate. If exit pressure and velocity were uncoupled this would be true. However, the nozzle exit pressure and velocity are very closely and adversely coupled through the amount of nozzle expansion. Since the flow is supersonic, the exit velocity will increase and exit pressure decrease as $\varepsilon$ is increased and vice versa as $\varepsilon$ is decreased. It can be shown that optimum performance is obtained if the nozzle exit pressure is equal to the atmospheric pressure, $p_{e}=p_{a}$, i.e. for adapted (or ideally expanded) flow. This is illustrated in Figure 3, which shows how the specific

${ }^{2}$ Sometimes $g_{0}=9.81\left(\mathrm{~m} / \mathrm{s}^{2}\right)$ is included in the denominator to make the performance value independent of the used unit system, i.e. the unit for $I_{s p}$ changes from a velocity $(\mathrm{m} / \mathrm{s})$ to a time $(\mathrm{s})$. 


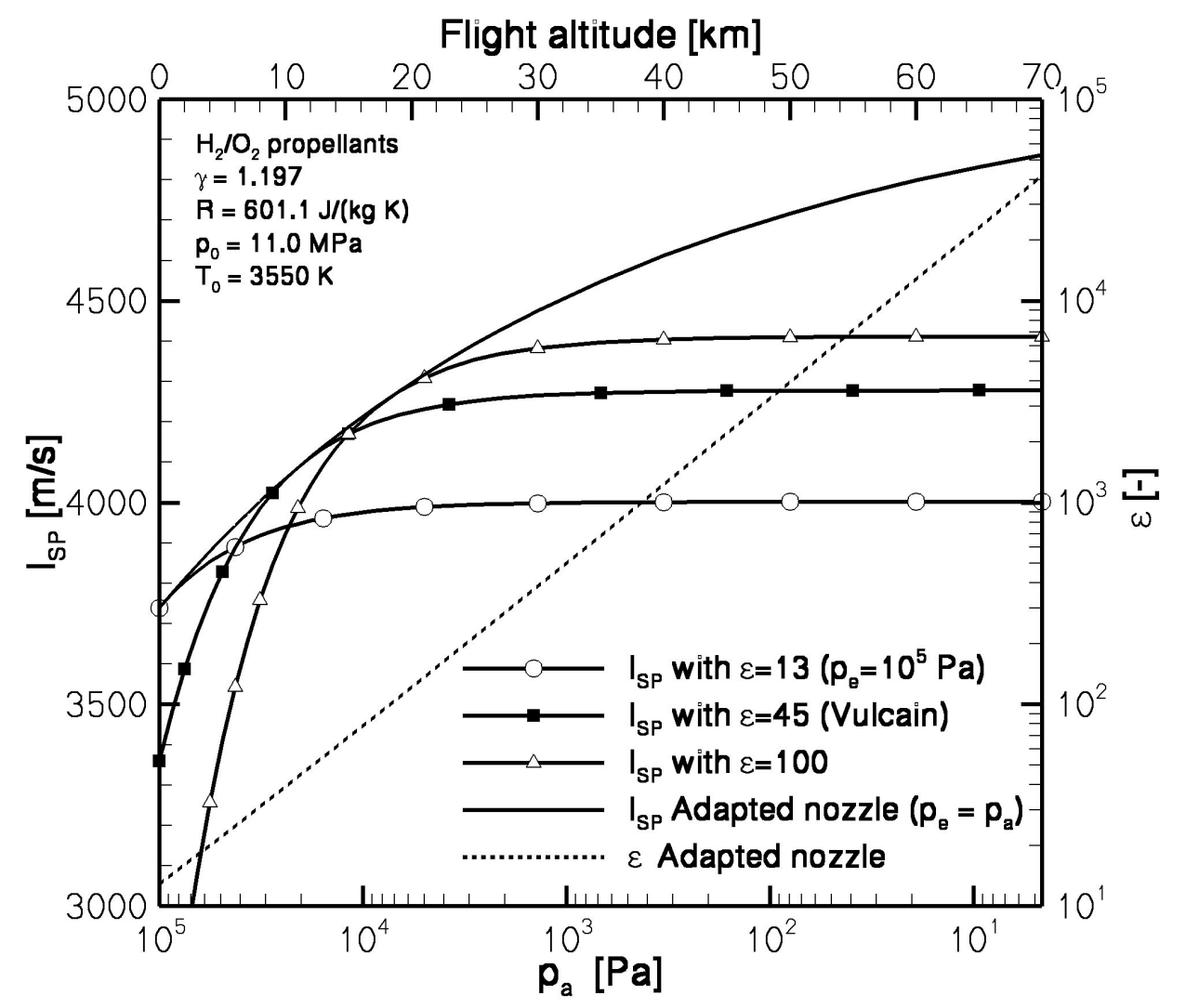

Figure 3. Performance versus ambient pressure.

impulse varies with ambient pressure (or flight altitude) for given chamber conditions equal to that of the Vulcain engine ${ }^{3}$. The solid lines show the specific impulse, the ones with symbols are for nozzles with fixed expansion ratio, and the one without symbols for an adaptable nozzle (able to change $\varepsilon$ to adapt the exit pressure to the ambient pressure). The dashed line shows the corresponding expansion ratio of the adaptable nozzle. With a nozzle expansion ratio of $\varepsilon=45$, the flow becomes ideally expanded at an altitude of $10 \mathrm{~km}$. From ground level up to this altitude the flow is overexpanded, i.e. $p_{a}>p_{e}$, while it is underexpanded $\left(p_{a}<\right.$ $p_{e}$ ) at higher altitudes. The flow patterns in the exit jet for the different regimes are illustrated by the numerical Schlieren pictures of Figure 4.

So far we have only described how a rocket engine is working and nothing has been said about the demands a rocket launcher need to fulfill and how it is done.

\footnotetext{
${ }^{3}$ The Vulcain engine is used as the core stage engine on the European Ariane 5 launcher.
} 


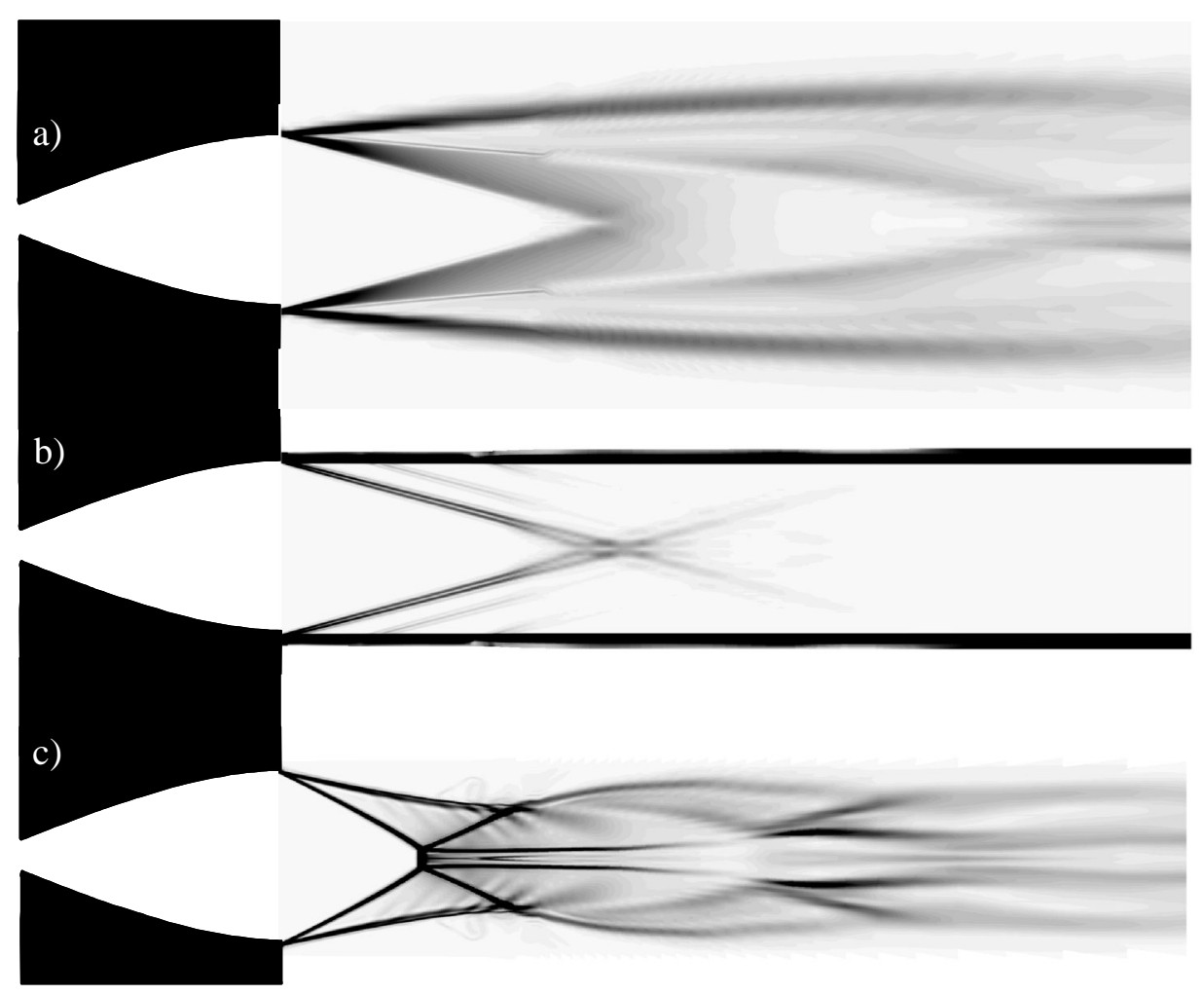

Figure 4. Numerical Schlieren pictures of flow at exit of a Mach 4 nozzle. a) Under- $\left(p_{e} / p_{a}=2\right)$, b) Ideal $\left(p_{e} / p_{a}=1\right)$ and c) Over- $\left(p_{e} / p_{a}=0.3\right)$ expanded flow.

To escape from Earth's atmosphere a launcher has to travel at least $150 \mathrm{~km}$ at a speed of more than $7.9 \mathrm{~km}$ per second. If the velocity were less the launcher would not be able to escape the Earth's gravitational attraction and if a satellite were put into lower orbit it would be pulled back into the Earth's atmosphere and rapidly burn up. When sorting out all parameters it will be found that weight is allimportant. The heavier the payload the more fuel the launcher has to carry to ensure liftoff. More fuel means bigger tanks and yet more weight. A delicate balance has to be found between the weight of the launcher and ensuring that it has enough fuel and power to accelerate fast enough to reach its orbit before falling to the ground. For this reason, most launchers have three stages, each stage dropping away once it has fulfilled its purpose. In this way launchers become progressively lighter and require less fuel. The launcher can either use serial staging, i.e. where the subsequent stage starts to operate first when the launcher jettisons the previous stage, or parallel staging where two stages operates simultaneously. 


\section{The Main Design Issue of Core Stage Engine Nozzles}

Most of today's launch vehicles, e.g. the American Space Shuttle, the European Ariane 5 launcher and the Japanese H-2 launcher, use parallel staging with two or more strong solid rocket boosters and a liquid core stage engine. The latter is ignited at ground to increase the reliability of the launcher and operates up to high altitudes, where the ambient pressure is close to vacuum. During take-off and the first phase of flight, the strong boosters make up most of the thrust, whereas the contribution of the core stage is comparably small. After booster separation, which usually takes place in altitudes where the ambient pressure is very low, the core stage alone accelerates the launcher. This is illustrated in Figure 5, which shows a typical flight sequence of a Geostationary Transfer Orbit mission for Ariane 5. With this type of staging, the vacuum performance of the core stage engine has a considerable influence on the payload, whereas its sea-level impulse is of minor importance (see Figure 3). The performance of rocket engines is highly dependent on the aerodynamic design of the expansion nozzle, the main design parameter being the area ratio as shown above. An obvious way to enhance the payload of such launchers is hence to increase the area ratio of the core engine nozzle, however, this will at the same time reduce the nozzle exit pressure.

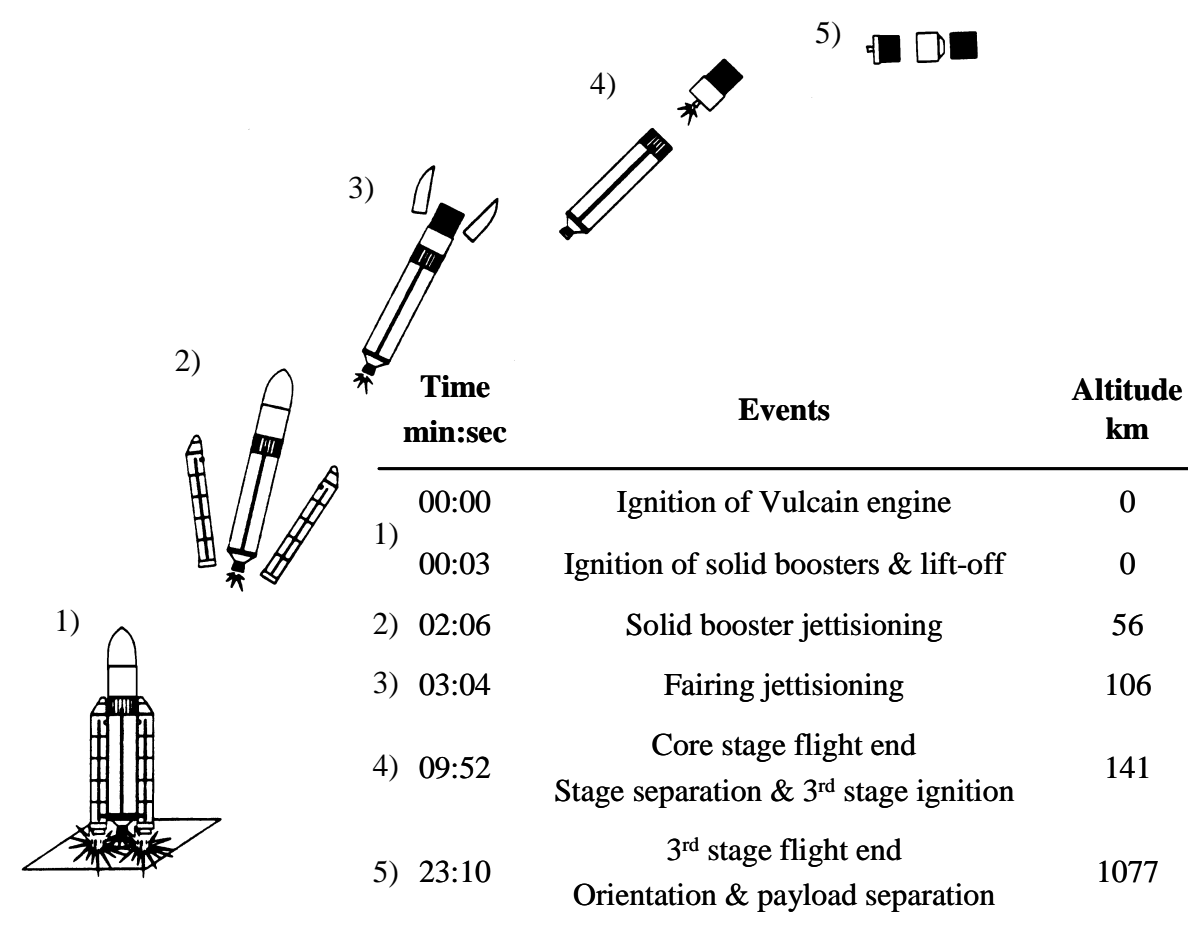

Figure 5. Typical flight sequence of an Ariane 5 GTO mission.

(Adopted from Isakowitz [2]) 
If a rocket engine is operated with the ambient pressure considerably higher than the nozzle exit pressure, the flow will not be fully attached, but separated from the nozzle wall. Flow separation in rocket nozzles is undesired because it can lead to high dynamic loads, which can damage the nozzle and end-up with a serious failure of the launcher. The most well known of these loads being the so called side-load, that has attracted the attention of many researchers. In order to prevent flow separation and side-loads, the core stage nozzles of today's launch vehicles use area ratios that are far below the optimum, but ensure full-flowing and thus safe function at sea-level conditions. Hence, allowing flow separation in the core stage engine with reduced side-loads would considerably improve the launcher's payload and thereby meeting the increasing demands from the satellite market.

One possible solution of the described problem is to adapt the nozzle contour during the flight to the changes of ambient pressure as shown in Figure 3. Attempts in this direction, however, have not yet been successful due to weight and mechanical complexity of such adapting devices.

Another approach is to introduce so called Flow Separation Control Devices (FSCD), by which high area ratio nozzles can be operated at separated condition at high ambient sea-level pressure without severe loads, thereby obtaining an improved overall performance. The feasibility of such devices is presently the objective of demonstration tests [3]. The main reason why such devices do not yet exist in full scale is that several basic questions regarding the nature of the flow separation phenomena and corresponding side-loads remain to be answered, which means that basic research is needed.

\section{Undesirable Effects Associated with Flow Separation}

Flow separation is a natural phenomenon as well as an engineering problem of fundamental importance in numerous industrial applications. It occurs in a wide range of flow regimes - laminar or turbulent, incompressible or compressible, subsonic or supersonic. In most cases it is an undesirable phenomenon because it is associated with large energy losses, or - as is the case in rocket engine nozzles high levels of unsteady lateral forces, the so-called side-loads. Other examples where flow separation is present are cars and ducts in the subsonic regime, and in the supersonic regime missiles, airbreathing transatmospheric vehicles and spacecraft.

When a supersonic flow is exposed to an adverse pressure gradient it adapts to the higher-pressure level by means of a shock wave system. Basically, separation occurs when the turbulent boundary layer cannot negotiate the adverse gradient imposed upon it by the inviscid outer flow. Thus, flow separation in any supersonic flow is a process involving complex shock wave boundary layer interactions (SWBLI). 
The interaction of shock waves with turbulent boundary layers can pose significant problems in the design of high-speed vehicles. When the flow is separated, large fluctuating pressure loads occur and can have characteristic frequencies close to the resonant frequencies of vehicle structural components. Interactions can arise from a variety of sources such as surfaces protuberances (wing-body junctures, antennae), abrupt turning of the high-speed flow (engine inlets, deflected elevons), and incident shocks originating from other parts of the vehicle. Since these types of loads are severe, always present during flight and cannot be avoided, it has been extensively studied in the last fifty years in order to understand and find ways to predict and reduce the loads.

Compared to the massive work focused on dynamic loads generated by SWBLI in external flow, the number of studies performed on internal flow separation in rocket nozzles has been meager in the past, see e.g. Refs. [4-31]. As a consequence the understanding of rocket nozzle flow separation and the ensuing side-load phenomena was limited when this project was initiated in 1997. The main reason is that flow separation and side-loads in rocket nozzles became a serious issue first in the 1970's when the development of the American Space Shuttle was initiated, i.e. the first launcher using parallel staging with a high performance core stage engine. Further, a core stage engine nozzle can be designed so that flow separation is avoided at nominal sea level steady-state operation. Thereby limiting the period of time with flow separation in the nozzle to the start-up (and shut-down) transient of the engine.

The following milestones give a historically perspective of the understanding of the side-load phenomena

1. 1970's development of the American Space Shuttle Main Engine (SSME): Experimental studies are performed by Nave \& Coffey [4] to investigate flow separation and the side-load phenomena in rocket nozzles for obtaining SSME design information. For the first time measurement results of side-loads become public available. It is observed that the flow separation and side-load characteristics are different in the full-scale and the sub-scale model engine tests. In contrast to the full-scale tests a transition between two different separations patterns, from "Free Shock Separation" (FSS) to "Restricted Shock Separation" (RSS), are observed in the model tests. In FSS the flow separates from the wall and continuous as a free stream. In RSS the flow separates and reattaches to the wall forming a small-restricted region with recirculating flow. It is also found that this flow phenomenon includes a hysteresis effect, i.e. the transition from FSS to RSS and from RSS back to FSS does not occur at the same operational condition. Further, significant side-loads are 
obtained in both the FSS and RSS region, whereas the side-load activity is at a minimum in the hysteresis region. No explanation is given why the model nozzles features both separation patterns whereas the full-scale engine only has FSS.

2. 1974: According to Schmucker, side-loads in rocket engine nozzles are due to asymmetric fluctuations of the separation line. He purposed a quasi-static side-load model based on a tilted separation line assumption, i.e. an asymmetric pressure distribution, which is acting over an effective area [5]. Schumcker's correlates his model with the side-load data by Nave \& Coffey [4].

3. 1980's development of the European core stage engine Vulcain: Schmucker side-load model is used in the design work.

4. 1981 SSME fuel feed line failure investigation: Unexpectedly large loads during SSME engine start and cutoff transients cause fatigue failure of the fuel feed line. Larson et al. [6] conduct cold gas tests to investigate the side-load activity at the nozzle exit of a sub-scale SSME nozzle. With help of fluctuating wall pressure measurements and high-speed Schlieren movies of the flow, they find that the cause of the failure is due to unsteady flow separation at the nozzle exit. It is observed that the flow separates from and reattaches to the wall at the nozzle exit in a cyclic manner with a frequency of $100 \mathrm{~Hz}$. It is the first time this phenomenon is reported and Larson et al. does not correlate theses observations with the appearance of RSS found in the earlier sub-scale tests performed by Nave \& Coffey [4].

5. 1989 first Vulcain engine test: Unexpected high levels of side-loads are observed. It is concluded that the Schmucker model is too simple.

6. 1994: Pekkari claims that side-loads in rocket engine nozzles are due aeroelastic instability [8-9]. Based on an aeroelastic model, Pekkari conclude that the "model results are qualitatively as well as quantitatively consistent with Vulcain test results".

7. 1996: Dumnov reports that side-loads are due to random pressure fluctuations, similar to those observed in external SWBLI [7]. Dumnov proposes a dynamic side-load model based on a generalized pressure fluctuation function. The application of the model to Russian rocket nozzles gives reasonable agreement between measured and predicted side-load. However, the model cannot reproduce the sideload feature of the Vulcain nozzle.

8. 1997-1998 Sub-scale testing of a Vulcain nozzle: Mattsson et al. [32] investigates the flow separation and side-load phenomena in a sub-scaled Vulcain nozzle. They re-discover the FSS-RSS transition. They also find that a significant side-loads pulse is generated during the FSS-RSS transition inside the nozzle. Further, a second side-load peak is observed as the RSS is converted to FSS at the nozzle exit. The findings initiate a renewed interest of RSS phenomenon. Possible 
aeroelastic effects are also investigated by changing the mechanical stiffness of the model nozzle. Mattsson [33] find that the aeroelastic coupling effects are not as strong as Pekkari anticipated. However, Mattsson also shows that a significant aeroelastic amplification of side-loads can occur in weak nozzle structures. These conclusions later becomes more public available through the work by Östlund $e t$ al. $[3,34]$.

9. 1998: Frey et al. [35] shows that the appearance of RSS is closely linked to the internal shock generated in non-ideal nozzles, such as the thrust optimized Vulcain and SSME nozzle.

10. 1999: Based on the recent findings, Terhardt et al. [36] re-evaluates Vulcain test data. The re-evaluation confirms that the transition between separation patterns observed in the Vulcain sub-scale tests by Mattsson et al. [32] also are the key driver for the large side-loads experienced in the Vulcain rocket engine.

11. 1999-present date: Thanks to the focused work aimed to investigate flow separation and side-load origins, performed by the author and other European researchers during recent years [37-39], a major break-through regarding the physical understanding of nozzle dynamics has been done. Today we know that the problem of sideloads is substantially more complex than previously realized. Sideloads are generated not by one but by a variety of physical mechanisms, depending on nozzle contour type, mechanical structure and ambient conditions.

\section{Development Logic for Nozzle Design}

The positive results obtained during recent years concerning separation and sideload behavior are the fruit of combined analytical, numerical and experimental efforts, where CFD has been employed to support the design of test models, and tests have furnished input for refinement of CFD-methods, thus achieving a physical understanding of the flow processes that would not have been possible only a generation ago.

A schematic of the development loop is shown in Figure 6. A design loop usually begins with a contour layout, where the Method Of Characteristics (MOC) and/or other CFD methods are used to optimize the aerodynamic performance for a given design specifications (e.g. length, area ratio, weight etc). The next step is to verify, and if necessary modify, the design so as to meet specified load requirements. For this it is necessary to know pressure and temperature loads acting on the wall, but it is also necessary to assess internal flow field, in order to predict the flow regime at each given operational conditions. This is done using a combination of numerical and experimental methods. CFD methods are usually calibrated and validated in a specific flow regime, and hence may only give reliable results as 


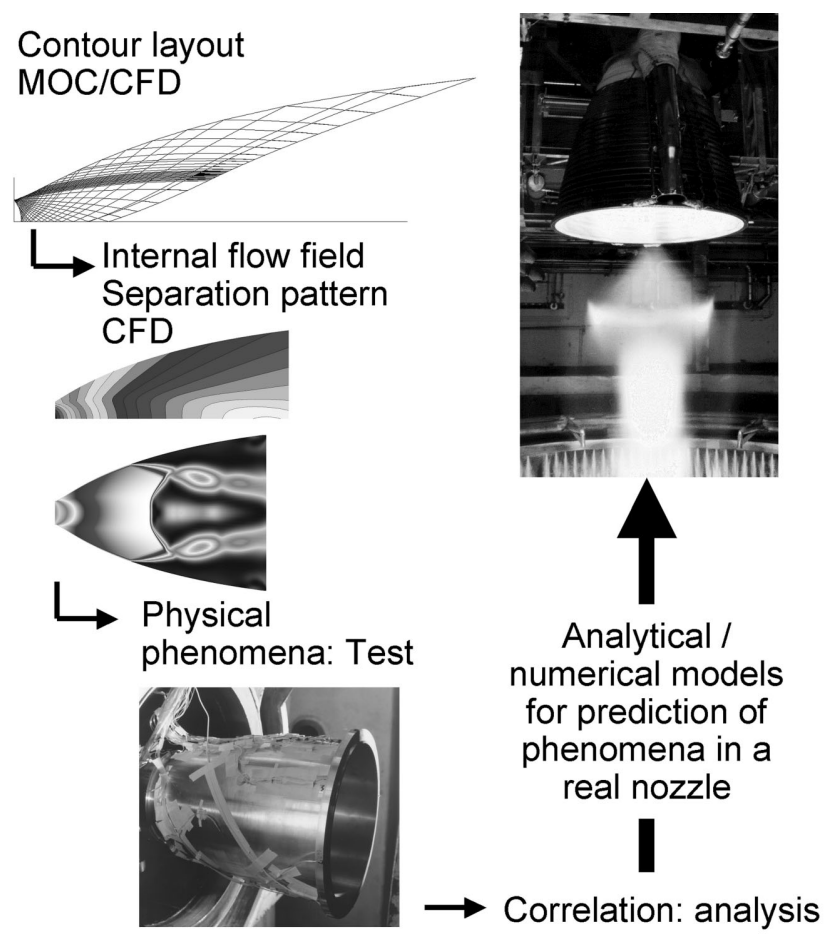

Figure 6. Logic of nozzle development.

long as the flow remains within the same regime. It is therefore imperative to perform hardware tests in order to verify that the nozzle flow actually lies within this regime. Most test methods, on the other and, can only access wall properties and hence experimental results on the internal nozzle flow field are usually not available. Flow measurements and visualization therefore need to be used interactively with CFD in order to draw conclusions concerning the physical mechanisms at work. In this process, the engineer will arrive at generalized correlations, which serve to evaluate a given design. A last step will be to apply these to the full-scale nozzle operating with real combustion gases on the rocket engine, which may require yet another loop of interaction between test, CFD and analysis.

Figure 7 shows some typical test configurations and how they relate to the fullscale engine nozzle in terms of complexity of the setup versus representativity of the obtained results. Which type of test to perform will depend on the stage of development, i.e. whether one is interested in general results of a fundamental character or data for a specific design. 


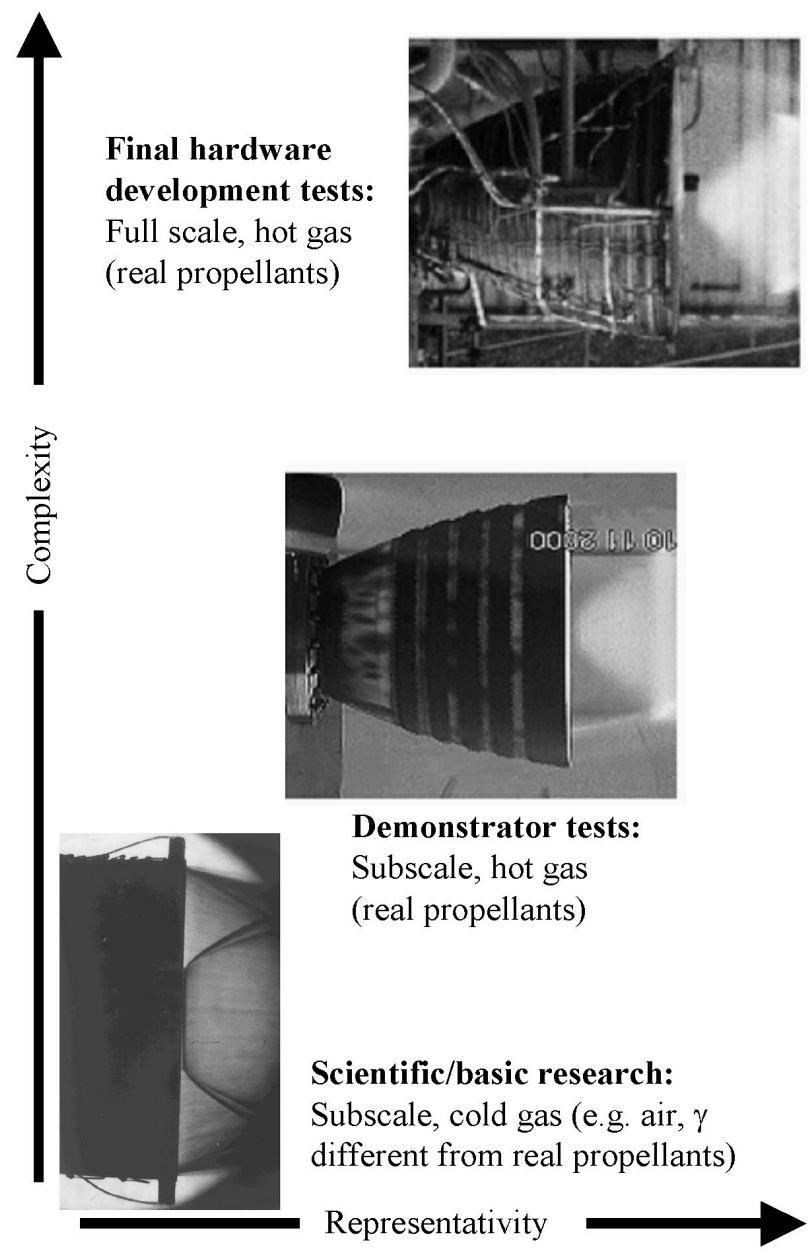

Figure 7. Subscale model testing.

Subscale model experiments are basically of two kinds:

(i) Hot gas tests, using gases with the same physical properties as a full-scale propellant gas. This allows for a simple geometric scale-down, leaving dynamical parameters unchanged. This type of sub-scale tests was performed e.g. during the development of the Vulcain engine [40] and also recent in demonstrator test of a radiation cooled $\mathrm{C} / \mathrm{SiC}$ nozzle extension [41]. In both of these cases, the test model was a complete scale-down of the Vulcain nozzle. As expected the separation characteristics in the scaled nozzles [40, 41] showed close agreement with the Vulcain nozzle $[36,42]$. For instance, the transition of the separation pattern inside the nozzle from FSS to RSS and the transition from RSS to FSS at the exit of the nozzle occurred at the same operation conditions as in the Vulcain nozzle. 
However, the test and instrumentation cost for this kind of test is high, and the high temperature imposes severe limitations on the measurement equipment that can be used. The obtainable information is further restricted by the test duration time, which is usually short due to test rig limitations. It is therefore necessary to complement with wind tunnel testing, where the test duration can be significantly increased.

(ii) Cold gas tests, using e.g. air $(\gamma=1.4)$ instead of hot gas propellants (e.g. $\gamma \approx$ 1.2 for engines operated with $\mathrm{H}_{2}-\mathrm{O}_{2}$ ), are a relatively inexpensive alternative, allowing for more extensive testing, and parameter variation. The draw-back is that it is no longer possible to separate geometrical and dynamical parameters, since all gasdynamical quantities are functions of both Mach number and $\gamma$. In this case CFD is indispensable as a tool to define appropriate test models as well as making meaningful test evaluations. The main challenge in such tests is to reproduce the actual behavior of a nozzle run with hot propellants.

In the present context, the main scaling requirement is that the model nozzle should have similar separation and side-load characteristics as the original. This means that the essential features of the interior flow field must be reproduced, while maintaining a similar wall pressure distribution. These requirements cannot be simultaneously fulfilled, if the gas used to operate the model does not have the same $\gamma$ as in the real nozzle as shown by Östlund [37]. Nevertheless, direct scaling from cold to hot flows is possible within certain limits if the cold-gas contouring is done very carefully and if the right values are used for normalization [37]. Of course, cold-gas test results can always be used to understand the physical phenomena and establish prediction tools, which can be applied to hot full-scale applications $[37,41]$.

In the following sections the current authors contribution to the understanding and modeling of supersonic flow separation and the ensuing side-load phenomenon in rocket engine nozzles is presented. 


\section{SUMMARY OF PAPERS}

Building of knowledge regarding flow separation and side-loads has been a continuous process at Volvo Aero Corporation (VAC) since 1993, when the Flow Separation Control working (FSC) group was formed with CNES, SNECMA and ASTRIUM $^{4}$.

VAC performed focused studies on the topic within the GSTP/FSC program, 1996-1999, under a contract with the European Space Agency (ESA) and the Swedish National Space Board (SNSB). This included sub-scale testing of rocket nozzles at the modified hypersonic wind tunnel HYP500 at the Aeronautical Research Institute of Sweden (FFA)*, in order to investigate the aerodynamic and aeroelastic behavior of a parabolic contour with and without FSCD inserts. The present author has been actively involved in the VAC/FSCD activities since 1997, being in charge of the test design (including design of model contours), hardware set-up and instrumentation, as well as test logic and evaluation of test results. In Paper I a description of the GSTP test program is given, together with discussion and analysis of the obtained test results.

In the subsequent FSCD-program since 1998, under contract with Swedish National Space Board (SNSB) and Centre National d'Études Spatiales (CNES), flow separation and side-loads have been studied analytically and experimentally in sub scale test campaigns and this work is partly presented in Paper II. This work was performed in co-operation with FOI, CNES, SNECMA, ONERA, LEA, DLR and ASTRIUM [38-39].

Throughout the work, CFD-computations have been extensively used for designing the models. They are indispensable for a qualitative understanding of the physics and flow phenomena, and hence provide a necessary input for setting up model descriptions and making meaningful evaluations. During the initial phase of the GSTP program, CFD studies were performed in order to investigate the capability of some standard RANS models for predicting flow separation in nozzles. These studies showed that all standard 2-equation models tested severely failed to predict this type of flow field. To cure the apparent anomaly in the RANS simulations an ad hoc realizability correction was introduced, which showed to improve the prediction. These predictions are compared with test data in Paper I. Based on these experiences a new study was initiated together with FFA to assess the influence of different corrections. The result from this work is presented in Paper III. Besides this work, an overview and analysis of the most commonly used corrections of RANS models is given in Paper V.

\footnotetext{
${ }^{4}$ is now a part of EADS Space Transportation

* is now a part of the Swedish Defence Research Agency (FOI)
} 


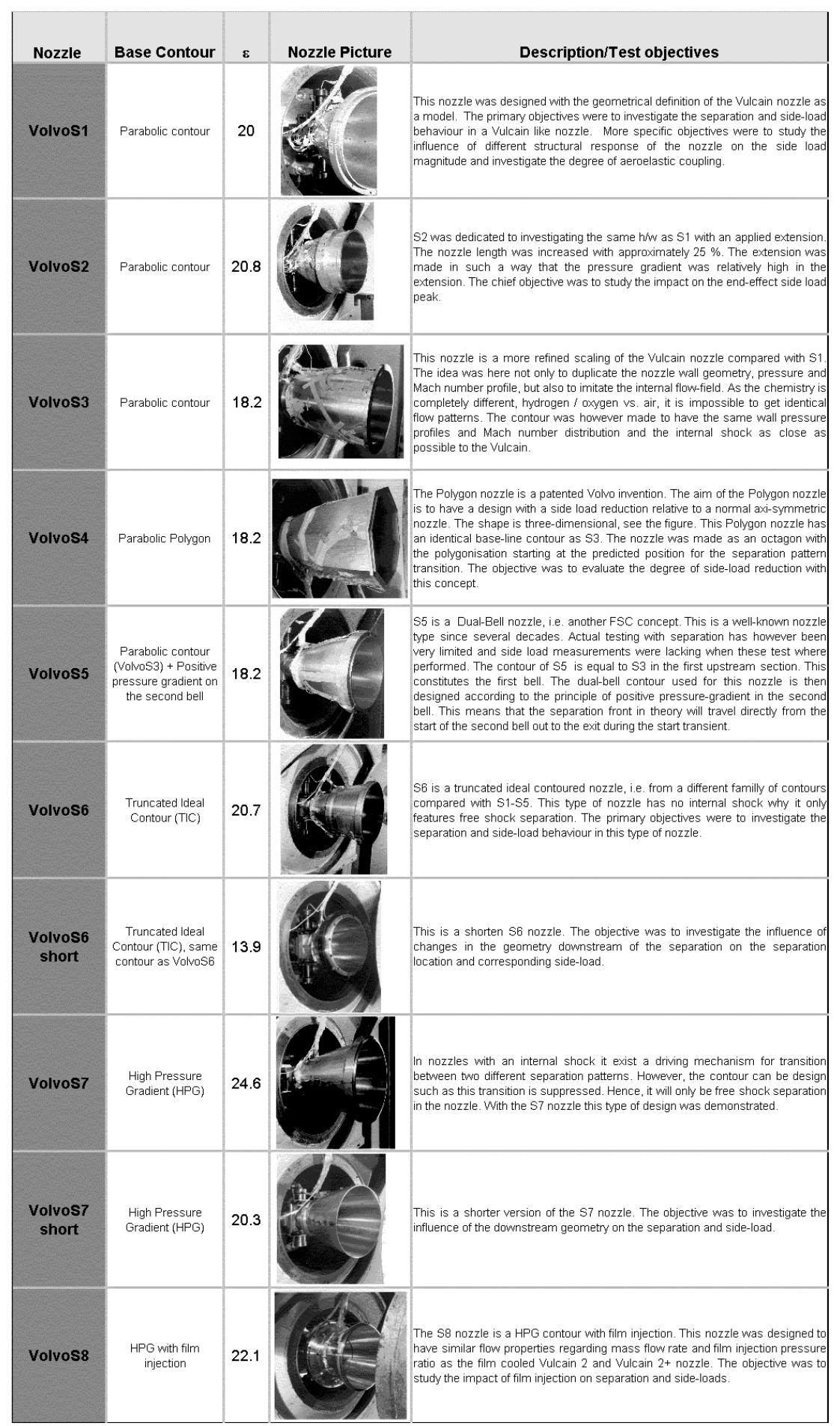

Table 1. Sub scale nozzles tested by VAC at FFA's HYP500 facility. 
Within the frame of the FSCD-program, VAC performed new sub-scale nozzle tests at FFA's test facility in Stockholm. In the FSCD program VAC has tested eight different nozzle concepts, which are listed in Table 1. Three potential origins of side-loads have been observed and investigated - namely the pressure fluctuations in the separation and recirculation zone due to the unsteadiness of the separation location, the transition of separation pattern and the aeroelastic coupling. In Paper IV, all three mechanisms are described in detail, and methods are presented to calculate their magnitude and pressure ratio of occurrence. In Paper V the nozzle flow separation phenomena is put in a wider perspective. This paper gives an introduction to the physical background, and an overview of methods of research, modeling and prediction, and important achievements, starting with boundary-layer interactions in basic configurations and then proceeding to the more complex case of rocket engine nozzles.

\section{PAPER 1}

Mattsson J (changed name to Östlund 1999), Högman U and Torngren L

"A Sub-Scale Test Programme on Investigation of Flow Separation and SideLoads in Rocket Nozzles', In Proceedings of the 3rd European Symposium on Aerothermodynamics of Space Vehicles, ESA-ESTEC, Netherlands, November 24-26, 1998, ESA SP-426

\section{Significance of work}

This paper gives a description of a subscale test program aimed to investigate the flow separation and side-load phenomenon in parabolic bell shaped rocket nozzles. The tested nozzle was a subscale model of the Vulcain nozzle. The results show that there is a transition of separation pattern in the nozzle, from the free-shock separation (FSS) to the restricted shock separation (RSS) pattern. This type of transition was observed already in the 1970's by Nave \& Coffey [4]. However, in this work it was shown, for the fist time, that these transitions also are the origin of two distinct side-load peaks. This conclusion was the ignition for intensive research of the phenomenon both within and outside Europe. Further subscale experiments were performed within different FSCD test campaigns $[3,43,44]$ as well as recent Japanese experiments [45], which confirmed this mechanism for side-loads in TOP and CTIC nozzles (both of which have an internal shock). In addition, re-evaluation of test results of the Vulcain rocket engine confirmed this mechanism as key driver for side-loads during both start-up and shut-down [36].

\section{Division of work by authors}

Jan Mattsson has been in charge of the test design, hardware set-up and instrumentation, as well as test logic and evaluation of test results. The tests were 
performed at FOI by Lars Torngren and his colleges. The work was led by Ulf Högman. The paper was written by Jan Mattsson. The work was performed within the ESA/ESTEC General Support Technology Program and has partly been presented by (i) Torgny Stenholm: Flow separation control activities at Volvo and SEP, ESA Advanced Nozzle Workshop, University of Rome, 14-15 October, 1997. (ii) Jan Mattsson: Subscale Testing of Flexible Nozzles, In Proceedings of European Seminar on Rocket Nozzle Flows, CNES, Paris, 12-14 October 1998.

\section{PAPER 2}

Östlund $\mathrm{J}$ and Bigert $\mathrm{M}$

"A Subscale Investigation on Side-Loads in Sea Level Rocket Nozzles"

Presented at $35^{\text {th }}$ AIAA/ASME/SAE/ASEE Joint Propulsion Conference and Exhibit, AIAA Paper 99-2759, June 1999

\section{Significance of work}

This paper gives a description of test objectives, results and conclusions of a subscale test program aimed to investigate the flow separation and side-load phenomenon in rocket nozzles with Flow Separation Control (FSC) or side-load reduction devices. The designed test set-up is unique in the sense that it resembles the bending mode of a real rocket nozzle. The influences of the degree of freedom of the nozzle motion and the bending resistance on the side-load magnitude were studied with the use of exchangeable torsions springs. Mainly two types of FSC nozzles were tested, i.e. a polygon shaped and a Dual-bell nozzle respectively. This work was the first actual side-load reduction demonstration with FSC concepts in a rig test. It was also the first work that showed that there can be both aerodynamic and aeroelastic drivers for the side-load. Further, a verified analytical model for the prediction of the transition of separation pattern from FSS to RSS is given in the paper. This model in parallel with the model by Frey et al. [42], were the first models aimed for prediction of this phenomenon.

\section{Division of work by authors}

Jan Östlund has been in charge of the test design, hardware set-up and instrumentation, as well as test logic and evaluation of test results. The work was led by Mikael Bigert. The paper was written by Jan Östlund and Mikael Bigert.

\section{PAPER 3}

Östlund $\mathrm{J}$ and Jaran M

"Assessment of Turbulence Models in Overexpanded Rocket Nozzle Flow Simulations", Presented at $35^{\text {th }}$ AIAA/ASME/SAE/ASEE Joint Propulsion Conference and Exhibit, AIAA Paper 99-2583, June 1999 


\section{Significance of work}

In this work it is shown that the choice of turbulence model has a significant influence on the simulated flow field in an overexpanded rocket nozzle. It is found that without corrections, standard two-equation turbulence models fails to predict the measured separation characteristics in the nozzle. The main source of the apparent anomaly in these simulations are located, namely the unphysical production of turbulent energy $\left(P_{k}\right)$ encountered at shocks. It is shown that the results can be improved when a physical limiter of $P_{k}$ is introduced. It is also shown that further improvements can be obtained with the use of a weakly nonlinear realizability correction, which limits the value of the eddy viscosity.

\section{Division of work by authors}

This work was initiated by Jan Östlund. The simulations were carried out by Matias Jaran under supervision of Jan Östlund. The paper was written by Jan Östlund and Matias Jaran.

\section{PAPER 4}

Östlund J, Damgaard T and Frey M

"Side-Load Phenomena in Highly Overexpanded Rocket Nozzles"

Accepted for publication in Journal of Propulsion and Power

\section{Significance of work}

This paper gives an overview of different side-loads mechanisms observed in the VAC nozzle test campaigns. Three main types of side-loads have been observed due to: (i) random pressure fluctuation, (ii) transition in separation pattern and (iii) aeroelastic coupling. All these three types are described and exemplified by test results together with analysis. A new approach for detection of the separation zone in nozzles is proposed based on general characteristics of the unsteady separated flow. It is shown that the dynamic separation process in rocket nozzles is very similar to the one observed in generic test cases. Hence, the intermittency of the nozzle flow can be described in similar manner as in generic test cases. Methods to translate aerodynamic forces to mechanical loads or vice versa are outlined. This includes solving a forced response problem for stationary and random forces and using pulse excitation theory for sudden and distinct forces. A major part of the work is devoted to the more complex case, i.e. when the separated nozzle flow interacts with the mechanical system. For the first time, an aeroelastic model for separated nozzle flow is presented and verified with test results. It is shown that the aeroelastic model is capable to predict the aeroelastic behavior experienced in the tests and that aeroelastic effects can be significant in week nozzle structures. 


\section{Division of work by authors}

Jan Östlund performed analysis and simulations. The results were discussed with Tomas Damgaard and Manuel Frey. The paper was mainly written by Jan Östlund. The paper is based on Östlund J, Damgaard T and Frey M, "Side-Load Phenomena in Highly Overexpanded Rocket Nozzles", $37^{\text {th }}$ AIAA/ASME/SAE/ASEE Joint Propulsion Conference and Exibit, AIAA Paper 2001-3684, July 2001.

\section{PAPER 5}

Östlund J and Muhammad-Klingmann B

"Supersonic Flow Separation with application to Rocket Engine Nozzles"

Accepted in revised form for publication in Applied Mechanics Reviews

\section{Significance of work}

This paper describes the current status of analytical, experimental and numerical research on shock-wave-boundary-layer interactions (SWBLI), where, however, emphasis is placed on the rocket-engineering perspective. The essential viscousinviscid interaction phenomena are explained in detail on the basis of analytical arguments. Fundamentals of SWBLI are reviewed. Subsequently the paper focuses on rocket-nozzle design issues and the fluid-mechanics phenomena affecting these. The paper also connects the industrial development of rocket engine nozzles to the fundamental research of the SWBLI phenomenon and show how these research results can be utilized in real applications. Aspects of scaling, testing and CFD modeling, which are specific for supersonic combustive flows, are highlighted. The paper is concluded with remarks on active and passive flow control in rocket nozzles and directions of future research.

\section{Division of work by authors}

This paper is based on the Licentiate Thesis by Jan Östlund, "Flow Processes in Rocket Engine Nozzles with Focus on Flow Separation and Side-Loads", Licentiate Thesis TRITA-MEK 2002:09, Royal Institute of Technology, Department of Mechanics, Stockholm, Sweden, 2002. The paper was written by Jan Östlund and Barbro Muhammad-Klingmann. 


\section{REFERENCES}

[1] Humble R W, Henry G N and Larson W J (1995), Space propulsion analysis and design, McGraw-Hill, Inc., ISBN-0-07031329-6.

[2] Isakowitz S J (1991), International reference guide to space launch systems, AIAA Technical Publications, Washington DC.

[3] Östlund J and Bigert M (1999), A subscale investigation on side-loads in sea level rocket nozzles, $35^{\text {th }}$ Joint Propulsion Conference and Exhibit, AIAA Paper 99-2759.

[4] Nave L H and Coffey G A (1973), Sea-level side-loads in high area ratio rocket engines, $9^{\text {th }}$ Propulsion Conference, AIAA Paper 73-1284.

[5] Schmucker R (1973), Flow processes in overexpanding nozzles of chemical rocket engines (In German), Report TB-7,10,-14, Technical University Munich, Munich.

[6] Larson E, Ratekin G, O’Connor G (1981), Structural response of the SSME fuel feedline to unsteady shock oscillations, $52^{\text {nd }}$ Shock and Vibration Symposium, New Orleans.

[7] Dumnov G E (1996), Unsteady side-loads acting on the nozzle with developed separation zone, $32^{\text {nd }}$ Joint Propulsion Conference and Exhibit, AIAA Paper 96-3220.

[8] Pekkari L-O (1993), Aeroelastic stability of supersonic nozzles with separated flow, $29^{\text {th }}$ Joint Propulsion Conference and Exhibit, AIAA Paper 93-2588.

[9] Pekkari L-O (1994), Aeroelastic analysis of side-loads in supersonic nozzles with separated flow, $30^{\text {th }}$ Joint Propulsion Conference and Exhibit, AIAA Paper 94-3377.

[10] Salikuddin M (1992), Unsteady pressures on exhaust nozzle interior surfaces - empirical correlations for prediction, $14^{\text {th }}$ DGLR/AIAA Aeroacoustics Conference, Proceedings. Vol. 2 (A93-19126 05-71), Bonn, Deutsche Gesellschaft fuer Luftund Raumfahrt, pp. 873-881.

[11] Darren R and Hidalgo H (1995), Fluctuating pressure analysis of a 2-d SSME nozzle air flow test, In its Thirteenth Workshop for Computational Fluid Dynamic Applications in Rocket Propulsion and Launch Vehicle Technology, (SEE N96-29750 11- 34) pp. 723-743.

[12] Foster C and Cowles F (1949), Experimental study of gas flow separation in overexpanded exhaust nozzles for rocket motors, JPL Progress Report 4-103, Jet Propulsion Lab., California Inst. of Tech., Pasadena, CA.

[13] Green L (1953), Flow separation in rocket nozzles, ARS Journal, 23(1).

[14] Summerfield M, Foster C and Swan W (1954), Flow separation in overexpanded supersonic exhaust nozzles, Jet Propulsion, 24.

[15] Campbell C and Farley J (1960), Performance of several conical convergent-divergent rocket type exhaust nozzles, NASA TN D-467, NASA Lewis Research Center, Cleveland OH.

[16] Schilling T W (1962), Flow separation in rocket nozzle, M. S. Thesis, University of Buffalo, New York.

[17] Kalt S and Badal D (1965), Conical rocket nozzle performance under flow separated condition, Journal of Spacecraft and Rockets, 2(3).

[18] Arens, M and Spiegler E (1963), Shock-Induced boundary layer separation in overexpanded conical exhaust nozzles, AIAA Journal, 1 (3).

[19] Sunley H and Ferriman D (1964), Jet separation in conical nozzles, Journal of the Royal Aeronautical Society, 68

[20] Lawrence R A (1967), Symmetrical and unsymmetrical separation in supersonic nozzles, Research report 67-1, Southern Methodist University, Dallas.

[21] Chen C, Chakravarchy S and Hung C (1994), Numerical investigation of separated nozzle flows, AIAA Journal, 32(9).

[22] Nasuti F and Onofri M (1996), Viscous and inviscid vortex generation during nozzle flow transients, $34^{\text {th }}$ Aerospace Sciences Meeting \& Exhibit, AIAA Paper 96-0076.

[23] NASA (1976), NASA space vehicle design criteria (chemical propulsion), liquid rocket engine nozzles, NASA SP-8120, Lewis Research Center, Cleveland $\mathrm{OH}$.

[24] Crocco L and Probstein R (1964), The peak pressure rise across an oblique shock emerging from a turbulent boundary layer over a plane surface, Princeton University, Princeton NJ.

[25] Carriere P (1966), Comments on computational methods of viscous effects in propulsion nozzles (In French), DGRR/WGLR Symposium, also published as ONERA TP 408 
[26] Carrière P, Sirieix M and Solignac J-L (1968), Propértiés de similitude des phénomènes de décollement laminaires ou turbulents en écoulemnt supersonique non uniforme, $12^{\text {th }}$ International Congress of Applied Mechanics, Stanford University, Stanford, also ONERA TP N ${ }^{\circ} 659 \mathrm{~F}$.

[27] Lewis J E, Kubota T and Lees L (1968), Experimental investigation of supersonic laminar, two-dimensional boundary layer separation in a compression corner with and without wall cooling, AIAA Journal, 6, 7-14.

[28] Dumnov G E, Nikulin G Z, Voinov A L and Zyuzin V I (1995), Nozzle flow separation and unsteady side-loads, Conference on Propulsive Flows in Space Transportation System, pp. 798-816.

[29] Kudryavtsev V M (1975), Fundamentals of theory and calculations of liquid rocket engines (In Russian), Moscow High School, Moscow.

[30] Malik T I and Tagirov R K (1988), A semiempirical method for calculating separated turbulent flow in a conical Laval nozzle in the reexpansion mode (In Russian), Akademiia Nauk SSSR, Izvestiia, Mekhanika Zhidkosti i Gaza , 60-66.

[31] Tuovila W J and Land N S (1968), Experimental study of aeroelastic instability of overexpanded rocket nozzle extensions, NASA TN D-4471, Langley Research Center, Langely Station, Hampton, Va.

[32] Mattsson J (changed name to Östlund 1999), Högman U and Torngren L (1998), A sub-scale test programme on investigation of flow separation and side-loads in rocket nozzles, Proceedings of the $3^{\text {rd }}$ European Symposium on Aerothermodynamics of Space Vehicles, ESA SP-426, 373-378.

[33] Mattsson J (changed name to Östlund 1999) (1998), Subscale testing of flexible nozzles, In Proceedings of European Seminar on rocket nozzle flows, CNES, Paris.

[34] Östlund J, Damgaard T, Frey M (2001), Side-load phenomena in highly overexpanded rocket nozzles, $37^{\text {th }}$ AIAA/ASME/SAE/ASEE Joint Propulsion Conference and Exhibit, AIAA Paper 2001-3684.

[35] Frey M and Hagemann G (1998), Status of flow separation prediction in rocket nozzles, $34^{\text {th }}$ Joint Propulsion Conference and Exhibit, AIAA Paper 98-3619.

[36] Terhardt M, Hagemann G and Frey M (1999), Flow separation and side-load behaviour of the Vulcain engine, $35^{\text {th }}$ Joint Propulsion Conference and Exhibit, AIAA Paper 99-2762.

[37] Östlund J (2002), Flow processes in rocket engine nozzles with focus on flow separation and side-loads, Licentiate Thesis TRITA-MEK 2002:09, Royal Institute of Thechnology, Stockholm, Sweden

[38] Hagemman G, Terhardt M, Frey M, Reijasse P, Onofri M, Nasuti F and Östlund J (2000), Flow separation and side-loads in rocket nozzles, $4^{\text {th }}$ International Symposium on Liquid Space Propulsion.

[39] Frey M, Ryden R, Aziary de Roquefort T, Hagemann G, James P, Kachler T, Reijasse P, Schwane R and Stark R (2002), European cooperation on flow separation control, $4^{\text {th }}$ International Conference on Launcher Technology "Space Liquid Propulsion".

[40] Stanke H (1986), Test report on the results on HM60-subscale test series 3, Vulcain Ne Project Report HM RT 1100000 501, MBB, Ottobrun

[41] Hagemann G, Alting J and Preclik D (2001), Scalability discussion for rocket nozzle flows based on subscale and fullscale testing, $4^{\text {th }}$ European Symposium on Aerothermodynamics for Space Vehicles.

[42] Frey M and Hagemann G (1999), Flow separation and side-loads in rocket nozzles, $35^{\text {th }}$ Joint Propulsion Conference and Exhibit, AIAA Paper 99-2815.

[43] Frey M, Stark, R, Cieaki H K, Quessard F and Kwan W (2000), Subscale nozzle testing at the P6.2 test stand, $36^{\text {th }}$ Joint Propulsion Conference and Exhibit, AIAA Paper 2000-3777.

[44] Reijasse P, Servel P and Hallard R (1999), Synthesis of the 1998-1999 ONERA works in the FSCD working group, ONERA RTS 49/4361 DAFE/Y, ONERA, Châtillon-sous-Bagneux.

[45] Tomita T, Takahashi M, Ueda S, Tamura H and Aoki K (2001), Visualization of the formation of separation bubbles on a bell-shaped nozzle surface in relation to serious side-load, $37^{\text {th }}$ Joint Propulsion Conference and Exhibit, AIAA Paper 2001-3559. 